\title{
A PERCEPÇÃO DOS ENFERMEIROS SOBRE EDUCAÇÃO PERMANENTE EM SAÚDE NO CONTEXTO DA ESTRATÉGIA SAÚDE DA FAMÍLIA DE SOBRAL (CE)
}

SOUSA, Maria do Socorro Teixeira de; BRANDÃO, Israel Rocha; PARENTE, José Reginaldo Feijão

\section{RESUMO}

O trabalho analisa a percepção dos enfermeiros sobre a educação permanente em saúde no contexto da Estratégia Saúde da Família no município de Sobral, CE. A pesquisa se orienta pela abordagem qualitativa, com uso de entrevista, realizada com 20 enfermeiros que atuam na Estratégia Saúde da Família do município. Os enfermeiros foram entrevistados em seus locais de trabalho com em horário previamente agendado. O percurso analítico-interpretativo dos dados foi realizado por meio da análise de conteúdo e segundo os referenciais teóricos da Política Nacional de Educação em Saúde. Os resultados revelam que os enfermeiros compreendem a educação permanente em saúde como atualizações, aquisição de novos conhecimentos através de conteúdos e aulas. O estudo aponta a necessidade de compreender a educação permanente em saúde a partir do conhecimento emergido das situações as quais envolvem os profissionais no seu cotidiano de trabalho, razão pela qual a torna importante para a transformação das práticas em saúde.

Palavras-Chave: Educação Permanente, Saúde, Enfermeiros.

\begin{abstract}
The work analyzes the perception of nurses on the permanent health education in the context of the Family Health Strategy in the city of Sobral, CE. The research is guided by the qualitative approach, with interview of use among 20 nurses working in the Health Strategy of the municipality's Family. The nurses were interviewed in their workplaces with in previously scheduled time. The analytical and interpretative route of the data was performed by means of content analysis and according to the theoretical framework of the National Policy on Education in Health. The results show that nurses understand the permanent health education as updates, acquiring new knowledge through content and classes, the study points to the need to understand the permanent health education from the knowledge emerged from situations which involve professionals in their daily work, why is important for the transformation of health practices.
\end{abstract}

Keywords: Permanent Education, Health, Nurses. 


\section{INTRODUÇÃO}

Em 2004, através da Portaria 198/2004 o Ministério da Saúde instituiu a Política Nacional de Educação Permanente em Saúde (PNEPS) como estratégia do Sistema Único de Saúde para a formação e o desenvolvimento de trabalhadores para o setor.

Esta política define a Educação Permanente em Saúde (EPS) como um instrumento para mudanças e transformações dos serviços de saúde. As transformações sociais e educacionais têm repercussões nos modos de produzir, nos diferentes campos do saber e de produção de bens e serviços (BALBINO et al., 2010).

Com efeito, as relações entre educação e trabalho em saúde assumem posições, estratégias e significados importantes, procurando vencer a dicotomia entre pensar e fazer e integrando habilidades teóricas e práticas. A EPS pretende incorporar o ensinar e o aprender ao cotidiano das organizações e do trabalho (BALBINO et al.,2010; CECCIM e FEUERWERKER, 2004).

Portanto, a EPS busca constantemente a aprendizagem, possibilitando processos e desenvolvimentos de profissionais de saúde para estarem comprometidos com a assistência, conscientes e responsáveis, inseridos no processo de trabalho e no território, conhecedores do sistema em que atuam, com suas políticas e ações (BALBINO et al., 2010).

Assim a EPS apresenta-se como proposta de ação estratégica capaz de contribuir para a transformação dos processos formativos, das práticas pedagógicas, de atenção a saúde e para a organização dos serviços, empreendendo um trabalho articulado entre o sistema de saúde, em suas várias esferas da gestão, e as instituições formadoras.

Nesse sentido, a educação permanente por ser um modelo inovador de buscar transformar uma realidade, deve ultrapassar os campos do saber focal dos profissionais e buscar o ensino-aprendizagem amplamente, a partir do seu dia-a-dia com a comunidade e assim, dar continuidade ao processo ensino-serviço.

No entanto, ainda se expressa frequentemente em nosso cotidiano de trabalho um modelo de formação tradicional através da educação continuada, a qual se constitui de cursos clássicos de atualizações profissionais, com sobrecarga, padronização, desarticulação com a gestão, reproduzindo-se um modelo hegemônico de atenção à saúde.

\section{REFERENCIAL TEÓRICO}

\subsection{A EDUCAÇÃO PERMANENTE EM SAÚDE NO CONTEXTO DO SISTEMA SAÚDE ESCOLA DE SOBRAL}

No município de Sobral, local onde ocorreu esta pesquisa, os processos de educação permanente são organizados e desenvolvidos através da Escola de Formação em Saúde da Família Visconde de SaboiaEFSFVS, que tem a missão de desenvolver o processo de ensino aprendizagem dos profissionais do Sistema Municipal de Saúde do Município de Sobral, tendo como instrumento a Educação Permanente.

Dentre os processos de educação permanente desenvolvidos pela Escola de Formação em Saúde da Família Visconde de Saboia destaca-se a educação permanente dos enfermeiros. De acordo com Sousa et al. (2008), com a implantação do Programa Saúde da Família (PSF), em 1997, as atividades da Enfermagem foram ampliadas, de forma a ultrapassar os limites do trabalho em diferentes ações: o enfermeiro passou a exercer suas funções na gerencia, na assistência de Enfermagem, nos cuidados domiciliares, na participação comunitária.

Apesar dos avanços percebe-se que ainda existem muitas fragilidades nos processos educativos destes profissionais. A formação e a educação dos enfermeiros necessitam de uma constante revisão para que as perspectivas de trabalho voltadas para a atenção a saúde na Estratégia Saúde da Família (ESF) sejam alcançadas.

Para tanto se exige uma releitura do contexto atual na busca de novas estratégias para a melhoria da atenção à saúde, e deve ser realizada tanto pelas instituições quanto pelos trabalhadores para que a 
educação permanente proponha novas ações no campo da educação em saúde o que orienta para o fortalecimento da relação educação trabalho (BRUM, 2009).

Portanto este estudo teve como objetivo compreender a percepção dos enfermeiros da ESF de Sobral sobre Educação Permanente em Saúde.

\section{METODOLOGIA}

O estudo de caráter descritivo exploratório com abordagem qualitativa. Neste tipo de abordagem o fenômeno humano estudado é entendido como parte da realidade social, pois este não se difere só por agir, mas por pensar sobre o que faz, e interpretar suas ações dentro e a partir da realidade vivida e partilhada com seus semelhantes (MINAYO, 2007).

A pesquisa ocorreu em Sobral, nos meses de janeiro, fevereiro e março de 2014, em doze Centros de Saúde da Família (CSF) da sede do município com a participação de 20 enfermeiros com tempo de atuação igual ou superior a dois anos na ESF de Sobral.

Para a construção do corpus da pesquisa utilizou-se a entrevista com roteiro semiestruturado onde os sujeitos tiveram a possibilidade de discorrer sobre o tema abordado.

O projeto de pesquisa foi submetido e aprovado em seus aspectos éticos e metodológicos pelo Comitê de Ética em Pesquisa da Universidade Estadual Vale do Acaraú (UVA), e a Comissão Científica da Secretaria de Saúde de Sobral, de acordo com as normas que regulamentam a pesquisa em seres humanos, do Conselho Nacional de Saúde, Ministério da Saúde, Resolução $n^{\circ}$ 466, de 12 de dezembro de 2012, sob o número 5053 de 20/12/2013.

Os dados foram tratados através da Analise de Conteúdo Temático conceituado por Bardin (2009). Segundo esta autora, a análise de conteúdo é um conjunto de técnicas de análise das comunicações, visando obter por procedimentos sistemáticos descrição do conteúdo das mensagens, indicadores que permitam a inferência de conhecimentos relativos às condições de produção/recepção (variáveis inferidas) destas mensagens. Tivemos como referenciais teóricos que permeiam a Política Nacional de Educação Permanente em Saúde. Foram operacionalizados seguindo as três etapas da análise temática: a pré-análise, exploração do material, tratamento dos resultados obtidos $\mathrm{e}$ interpretação. A fase de pré-análise, que se subdividiu em leitura flutuante e preparação do material, consistiu na organização dos dados, sistematizando as idéias iniciais, através da visualização individual de cada diálogo, onde se destacou os aspectos considerados relevantes.

Após a ordenação dos diálogos através da transcrição dos conteúdos foram feitas exaustivas leituras dos textos, organizando os relatos de modo a possibilitar o mapeamento das falas, agrupando-as por similaridade de idéias, assinalando as que tinham o mesmo significado ou semelhança, identificando as unidades significativas das falas a fim de que pudessem ser compreendidas e conscientemente exploradas. Esta forma de organização permitiu visualizar as seguintes temáticas: atualizações de conhecimentos, aprendizado permanente e processo formativo no trabalho apresentadas a seguir.

\section{RESULTADOS E DISCUSSÕES}

As percepções dos enfermeiros da Estratégia Saúde da Família sobre a Educação Permanente em Saúde foram organizadas em subcategorias que emergiram dos depoimentos dos sujeitos da pesquisa:

- Atualização de Conhecimentos

- Formação contínua que norteia o processo de trabalho

\section{Como Atualização de Conhecimentos} consideram a Educação Permanente uma ferramenta que consegue tirar dúvidas, atualizar, renovar e acrescentar seus conhecimentos, como pode ser constatado nos discursos:
"A Educação Permanente é
uma excelente ferramenta
para atualizar nossos
conhecimentos, tirar dúvidas, 
para facilitar o nosso trabalho." (Enf.01).

"Para os profissionais de saúde é muito bom, pois estão sempre atualizando os conhecimentos, renovando, não se fica desatualizado das coisas. Eu gosto muito de Educação Permanente" (Enf.03).

"Só veio pra contribuir, acrescentar conhecimento, renovar, e melhorar. Através da EP aprendemos a seguir os protocolos, trabalhar com mais segurança, estar atualizados, tirar dúvidas, a pessoa tem base, tem segurança pra aplicar na sua prática” (Enf.07).

Com este entendimento de que a educação permanente leva o profissional enfermeiro à competência, ao conhecimento e à atualização, que são componentes necessários para garantir a sobrevivência, tanto do profissional quanto da própria profissão.

Podemos observar através dos depoimentos que a percepção sobre Educação Permanente em Saúde focase em atualizações, novos conhecimentos, aprendizagem nos serviços. De acordo com os relatos, percebemos que as práticas de Educação Continuada são entendidas pela maioria dos enfermeiros como Educação Permanente.

Compreendemos que esse equívoco pode ter suas raízes no contexto o qual estamos inseridos, quando se atribui a qualquer atividade pedagógica relacionada aos serviços, o conceito de Educação Permanente.

Os sujeitos ao conceituarem a EPS como atualizações, aquisição de conhecimentos, afirmam que ao vivenciarem esta se sentem seguros para desenvolverem melhor as suas ações, como podemos observar no depoimento:

"Só veio pra contribuir, acrescentar conhecimento, renovar, só veio pra melhorar. Através da EP usando protocolos, trabalhar com mais segurança, estar atualizados, tirar dúvidas, a pessoa tem base, tem segurança daquilo que aprendeu pra aplicar na sua prática." (Enf. 7).

"Então eu vejo a Educação

Permanente como um instrumento bastante favorável para o aprendizado do enfermeiro $e$ consequentemente para uma boa realização do seu trabalho" (Enf.1).

Ao analisarmos essas percepções, buscamos na literatura as afirmações de Mejia (apud DAVINI, 1994), que conceitua educação continuada como o conjunto de experiências subsequentes à formação inicial, que permitem ao trabalhador manter, aumentar ou melhorar sua competência, para que esta seja compatível com o desenvolvimento de suas responsabilidades, caracterizando assim, a competência como atributo individual.

Entretanto, a abordagem da educação permanente pauta-se a partir do conhecimento emergido das situações as quais envolvem os profissionais no seu cotidiano de trabalho, razão pela qual a torna importante para a transformação do SUS e para o desenvolvimento dos profissionais inseridos neste.

Nas instituições de saúde há uma tendência em se acreditar que o domínio do conhecimento científico é fator primordial para a qualidade dos serviços. Muitas vezes, os profissionais realizam cursos de atualização, treinamentos e capacitações com a expectativa de transformar sua prática. Nesse contexto, predomina mais uma vez "[...] o valor do atributo conhecimento em detrimento do exercício de análise das condições concretas do processo de trabalho, que aponta a necessidade de intervenções múltiplas e criativas." (QUINTANA; ROSCHKE; RIBEIRO, 1994, p. 51).

No que se refere à Formação contínua que norteia o processo de trabalho, consideraram a EPS como um processo formativo contínuo capaz de dar continuidade à aprendizagem da graduação e que esta pode nortear para melhor organização dos serviços, conforme o que observamos nas falas abaixo:

"A EP significa uma continuação da faculdade, é quando você recebe conteúdos 
programáticos e estruturados para melhorar o seu trabalho no território." (Enf. 08).

"A EP serve para clarear tudo aquilo que a gente já viu na universidade há muito tempo, tanto dentro dos programas, da organização dos serviços, metodologias desenvolvidas, para que a gente possa planejar as ações na ESF." (Enf.17).

“A educação permanente é uma bússola, um norte, mas se esta bússola não é bem gerida, a gente se perde no meio do caminho. A organização do serviço se deu pela educação permanente. A EP é de grande valia. Dá certo quando queremos fazer." (Enf.19).

Reportando-nos a literatura sobre definições e conceitos da EPS, podemos identificar através da Política Nacional de Educação Permanente em Saúde, que a educação continuada tem como pressuposto pedagógico o conhecimento para definir as práticas; como objetivo, a atualização de conhecimentos específicos; percebe como público alvo os profissionais em suas especificidades, de acordo com os conhecimentos a serem trabalhados; a operacionalização é descendente, acontece a partir de uma leitura geral dos problemas, identificam-se temas e conteúdos a serem trabalhados com os profissionais, geralmente sob o formato de cursos. As atividades educativas são pontuais e fragmentadas, sendo construídas de maneira desarticulada em relação à gestão, à organização do sistema e ao controle social

(MOTTA, 2002; BRASIL, 2004; DAVINI, 2009).

Enquanto que a educação permanente em saúde segue os pressupostos pedagógicos apresentados pela OPAS/OMS, ainda na década de 80 , pois parte das práticas definidas por múltiplos fatores, conhecimentos, valores, relações de poder, organização do trabalho, entre outros, a aprendizagem significativa requer que se trabalhe com elementos que "façam sentido" para os sujeitos sociais envolvidos e os coloquem em posição ativa de propor e reordenar as práticas. O objetivo principal é a transformação real das práticas, o público alvo as equipes de atenção e de gestão multiprofissional e interdisciplinar em qualquer esfera do sistema. As atividades educativas são construídas de maneira ascendente, a partir da análise coletiva dos processos de trabalho, levando em conta as necessidades específicas de profissionais e equipes de saúde, identificam-se os "nós" críticos que devem ser enfrentados na atenção ou na gestão, o que possibilita a construção de estratégias contextualizadas que promovam o diálogo entre as políticas gerais e a singularidade dos lugares e das pessoas e conceitos (DAVINI, 2009; OPS/OMS, 2002; BRASIL, 2004; CECCIM, 2005).

Portanto, frente aos discursos dos sujeitos podemos perceber que as suas percepções sobre Educação Permanente estão muito próximas das que são definidas pela PNEPS como Educação continuada.

\section{CONSIDERAÇÃOES FINAIS}

No que se refere à percepção dos profissionais sobre Educação Permanente em Saúde (EPS) constata-se que estes compreendem a EPS como um processo de atualizações, novos conhecimentos e aprendizagem permanente, processo de formação contínuo. Constata-se que as práticas de Educação Continuada (EC) são entendidas como Educação Permanente.

Apesar da distinção entre as terminologias Educação Permanente em Saúde, Continuada e em Serviço, todas tem caráter de continuidade do processo educativo, porém se fundamentam em diferentes princípios metodológicos. A EPS, além da capacitação técnica é também um compromisso pessoal a ser conquistado com as mudanças de atitudes decorrentes das experiências vividas, por meio da relação com os outros, com o meio, com o trabalho, buscando a transformação pessoal, profissional e social. Parte da aprendizagem significativa para os sujeitos sociais envolvidos se coloque em posição ativa de propor e reordenar as práticas.

Esta pesquisa nos coloca frente a um compromisso ético e social com o Sistema Saúde Escola de Sobral, no qual propomos apoiar coletivamente na busca de novas possibilidades de reorganização da 
Educação Permanente em Saúde dos enfermeiros. E para tanto apontamos algumas recomendações: é necessário que os profissionais de saúde, gestores e facilitadores busquem compreender melhor a Política Nacional de Educação Permanente, suas diretrizes e bases metodológicas.

Vale lembrar que para se efetivar uma Política de EPS, são necessárias estratégias política, técnica e pedagógica. A avaliação do processo é de enorme importância para se consolidar novas práticas de saúde. Portanto, para se efetivar uma Política de EPS, são necessárias estratégias políticas, técnicas e pedagógicas.

\section{REFERÊNCIAS}

BALBINO, A. C.; BEZERRA, M. M.; FREITAS, C. A. S. L.; ALBUQUERQUE, I. M. N.; DIAS, M. S. A.; PINTO, V. P. T. Educação permanente com os auxiliares de enfermagem da Estratégia Saúde da Família em Sobral, Ceará. Trab. Educ. Saúde, Rio de Janeiro, v. 8 n. 2, p. 249-266, jul./out. 2010.

BARDIN, L. Análise de Conteúdo. Lisboa: Edições 70, 2009.

BRASIL. Ministério da Saúde. Portaria GM/MS no 198/2004, de 13 de fevereiro de 2004. Institui a política nacional de educação permanente em saúde como estratégia do Sistema Único de Saúde para a formação e o desenvolvimento de trabalhadores para o setor e dá outras providências,. Brasília: Ministério da Saúde, 2004. Disponível em: <http:// www.saude.gov.br/sgtes $>$ Acessado em 13 de jan, 2014

BRUM, L. M. A pedagogia da roda como dispositivo de educação permanente em enfermagem e a construção da integralidade do cuidado no contexto hospitalar. Rev. Gaúcha de Enfermagem, Porto Alegre, v. 31, n. 3, Sept. 2009.

CECCIM, R. B. Educação Permanente em Saúde: desafio ambicioso e necessário. Infertace Comunicação, Saúde, Educação, São Paulo, v. 9, n. 16, p. 161-77, set.2004/fev.2005. http://www.scielo.br/pdf/icse/v9n16/v9n16a13.pdf

CECCIM, R. B., FEUERWERKER, L. C. M. Mudança na graduação das profissões de saúde sob o eixo da integralidade. Cadernos de saúde pública. Rio de Janeiro, v.20, n.5, p. 1400-1410, Set./Out. 2004

DAVINI, M. C. Enfoques, Problemas e Perspectivas na Educação Permanente dos Recursos Humanos de Saúde. BRASIL, Ministério da Saúde (MS). Secretaria de Gestão do Trabalho e da Educação na Saúde (SGTES). Departamento de Gestão da Educação na Saúde (Deges) (Org.). Política Nacional de Educação Permanente em Saúde. Série Pactos pela Saúde 2006, v. 9. Brasília: Ministério da Saúde, 2009. p. 39-58.

DAVINI, M. C. Practicas laborales em los servicios de salud: lãs condiciones Del aprendizaje. In: Educación permanente de personal de salud. Serie Desarrollo de recursos humanos, n.100. Organización Panamericana de La salud. EUA, 1994.

MINAYO, M.C.S. O desafio do conhecimento: pesquisa qualitativa em saúde. São Paulo: Hucitec, 2007.

MOTTA, J. I. J. et al. Educação permanente em saúde, Revista Olho Mágico, Londrina, v. 9, n. 1, p. 68-73, 2002.

OPAS; OMS, Programa de Desarrollo de Recursos Humanos (HSR). División deDesarrollo de Sistemas y Servicios de Salud (HSP). La Capacitación Del Personal de los Servicios de Salud em Proyectos Relacionados com los Procesos de Reforma Sectorial. (Serie Observatorio de Recursos Humanos de Salud n. 3). Washington: OPS/OMS, 2002.

QUINTANA, P. B; ROSCHKE, M. A. C.; RIBEIRO, E. C. O. Educação permanente processo de trabalho e qualidade de serviço na saúde. Disponível em: <http://www.sesa.pr.gov.br >. Acesso em: 30 abr. 2014.

SOUSA, F.L; PONTE, M.A. C; LINHARES, A.K.N; CAVALCANTE, A.N;DIAS, M.S.A;SOARES, C; TAJRA, F.S; TEIXEIRA, E.H. A Política Municipal de Educação Permanente em Sobral- CE, in SANARE, v 7, n. 2, p 14-22, jul./dez. 2008 